\title{
Design of Switchable On/Off Subpixels for Primary Color Generation Based on Molybdenum Oxide Gratings
}

\author{
Gonzalo Santos ${ }^{1}$, Francisco González ${ }^{1}$, Dolores Ortiz ${ }^{1}$, José María Saiz ${ }^{1}$, Maria Losurdo ${ }^{2} \oplus$, Yael Gutiérrez ${ }^{2}$ \\ and Fernando Moreno ${ }^{1, *(\mathbb{D}}$ \\ 1 Department of Applied Physics, Universidad de Cantabria, Avda. Los Castros s/n, 39005 Santander, Spain; \\ gonzalo.santos@unican.es (G.S.); gonzaleff@unican.es (F.G.); ortizd@unican.es (D.O.); \\ saizvj@unican.es (J.M.S.) \\ 2 Institute of Nanotechnology, CNR-NANOTEC, Via Orabona 4, 70126 Bari, Italy; \\ losurdo.maria@gmail.com (M.L.); yael.gutierrezvela@nanotec.cnr.it (Y.G.) \\ * Correspondence: morenof@unican.es
}

Citation: Santos, G.; González, F.; Ortiz, D.; Saiz, J.M.; Losurdo, M.; Gutiérrez, Y.; Moreno, F. Design of Switchable On/Off Subpixels for Primary Color Generation Based on Molybdenum Oxide Gratings. Physics 2021, 3, 655-663. https://doi.org/ $10.3390 /$ physics 3030038

Received: 2 June 2021

Accepted: 9 August 2021

Published: 12 August 2021

Publisher's Note: MDPI stays neutral with regard to jurisdictional claims in published maps and institutional affiliations.

Copyright: (c) 2021 by the authors. Licensee MDPI, Basel, Switzerland. This article is an open access article distributed under the terms and conditions of the Creative Commons Attribution (CC BY) license (https:// creativecommons.org/licenses/by/ $4.0 /)$.

\begin{abstract}
Structural color emerges from the interaction of light with structured matter when its dimension is comparable to the incident wavelength. The reflected color can be switched by controlling such interaction with materials whose properties can be changed through external stimuli such as electrical, optical, or thermal excitation. In this research, a molybdenum oxide $\left(\mathrm{MoO}_{\mathrm{x}}\right)$ reflective grating to get a switchable on/off subpixel is designed and analyzed. The design is based on subpixel on and off states that could be controlled through the oxidation degree of $\mathrm{MoO}_{\mathrm{x}}$. A suitable combination of three of these subpixels, optimized to get a control of primary colors, red, green, and blue, can lead to a pixel which can cover a wide range of colors in the color space for reflective display applications.
\end{abstract}

Keywords: color reflective displays; phase-change materials; structural color

\section{Introduction}

For centuries, color has been a quite interesting topic for the scientific community [1,2]. The first systematic study was made by Newton when he performed his classical experiment, i.e., analysis and synthesis of light with a glass prism. Newton stated that the spectrum was constituted by seven colors: red, orange, yellow, green, blue, indigo, and violet. However, most colors in nature are not spectrally pure or able to fit in a small region of the spectrum, since they are often a result of a combination of phenomena. The color of a radiation depends not only on the reflectance-or transmittance-of the last object it went through, but also on the kind of illuminant and the photopic curve of the observer. Although a wide range of magnitudes can be used to characterize color, the best attributes according to the International Commission on Illumination (CIE) are chromaticity, brightness, and contrast [3].

Structural color is one of the most common manifestations of color in nature [4]. It is based on the selective light reflection depending on the interaction between light and structured matter (typically at nano- and microscale). This is the main pigmentary difference in which color is originated by the absorption of the electrons present in the pigment [5].

The most common mechanisms for obtaining structural colors are based on interference, diffraction, scattering, and photonic crystals [6]. Film interference can be considered as a typical Fabry-Perot (FP) effect. In such systems, light undergoes multiple reflections. When the optical path difference between two reflected rays is an odd multiple of a half of the incident wavelength, constructive interference takes place in specific spectral intervals and vivid colors can be generated. Many reflective displays are based on this phenomenon [7-11]. A typical configuration is a metal-insulator-metal (MIM) stack. A 
thin metal layer is used to control the spectral width of the reflectance peaks, a dielectric spacer tunes the resonant wavelength in the cavity, and a second metal layer works as a bottom mirror. However, if one looks for monochromatic intervals, there is an important drawback; these types of FP configurations generate reflectance resonances with a broad spectral width, and more than one resonance (second-order or even higher) is often generated, leading to undesirable resonance peaks in the visible range. This can be overcome by using diffraction gratings. They allow to generate narrow and isolated peaks in the visible part of the electromagnetic spectrum.

The diffraction effect by a grating is comparable to the multiple interference generated in FP cavities. The grating efficiency is determined by the period, functional shape of the profile, depth of the periodic structure, materials, angle of incidence and observation direction, wavelength, and polarization. Wood anomalies are known concept in the diffraction by periodic gratings [12]. The adjective "anomalies" is because, when discovered by R. Wood in 1902 [13], there was no clear explanation for the observation of narrow reflectance peaks in diffraction gratings. For metals, this is now explained because of surface plasmon excitation [12]. For dielectric gratings, the effect is due to the coupling of the propagating diffracted rays to the modes of the waveguide underneath, leading to guided mode resonances (GMR) [14,15]. The spectral width of a GMR is usually quite narrow; thus, as later shown, this is a favorable feature in terms of obtaining a wide color gamut. Although diffraction gratings have been proposed previously for their use on reflective displays [16-20], most of the gratings cannot control the reflectance for a fixed geometry. In this situation, only "static" colors are generated, which limits their potential as actively tunable color devices. A more recent study proposed a dielectric grating based on ITO to obtain an active color display by changing its permittivity with electrically tunable electron densities [21]. An alternative solution to the one proposed in [21] is the use of phase-change materials (PCM).

The most extended PCMs are chalcogenide materials. These are compounds of elements of the chalcogen group (sulfur, selenium, and tellurium) bound to network formers such as arsenic, germanium, antimony, and gallium [22]. They are known as the GST family due to the chalcogenide $\mathrm{Ge}_{2} \mathrm{Sb}_{2} \mathrm{Te}_{5}$, which has revolutionized the blooming field of phase-change photonics. The peculiarity of these materials is that they can be switched between their crystalline and amorphous phases by controlled electrical, optical, or thermal excitation $[23,24]$. This process leads to a modulation of their optical and electrical properties. Another known PCM is vanadium dioxide $\left(\mathrm{VO}_{2}\right) . \mathrm{VO}_{2}$ is a strongly correlated material that is dielectric at room temperature and becomes metallic in the infrared spectrum when heated at around $340 \mathrm{~K}$ [25-27]. On the other hand, molybdenum oxide $\left(\mathrm{MoO}_{\mathrm{x}}\right)$ presents a metal-semiconductor transition in the visible (Vis) spectrum, by changing its oxidation degree from $\mathrm{MoO}_{2}$ (metal) to $\mathrm{MoO}_{3}$ (semiconductor), which makes it suitable for applications in this range such as reflective displays among others [28]. Very recently, a switchable pixel based on an FP configuration with $\mathrm{MoO}_{\mathrm{x}}$ for color reflective displays was presented [29].

In this research, the design of a dielectric grating based on molybdenum oxide is proposed as a switchable on/off pixel for a color display. $\mathrm{MoO}_{\mathrm{x}}$ can be considered a nonvolatile phase-change material, i.e., it does not require a constant energy supply of energy to keep the switched state. It can exist as $\mathrm{MoO}_{2}$ or $\mathrm{MoO}_{3}$ and has a wide variety of nonstoichiometric oxides. The change in the oxygen content strongly affects the band structure and, consequently, its optical behavior. In $\mathrm{MoO}_{3}, \mathrm{O} 2 p$ orbitals give rise to the highest occupied states, wherein electrons are fully localized around the $\mathrm{O}$ atoms, giving a semiconducting behavior. However, the Fermi level of $\mathrm{MoO}_{2}$ is composed of $\mathrm{O} 3 d$ orbitals that present the characteristics of a metal [30]. Therefore, by changing the oxidation state from $\mathrm{MoO}_{3}$ to $\mathrm{MoO}_{2}$ a semiconductor-conductor-metal transition is triggered, allowing a modulation of the light-matter interaction. Interestingly, the literature shows that the intervalence charge-transfer modulation within diverse valence states of Mo, going from $\mathrm{Mo}^{6+}\left(\mathrm{MoO}_{3}\right)$ to $\mathrm{Mo}^{5+}$ and finally to $\mathrm{Mo}^{4+}\left(\mathrm{MoO}_{2}\right)$, can occur thermally by annealing at 
$400{ }^{\circ} \mathrm{C}$ in air (oxidation of $\mathrm{MoO}_{2}$ to $\mathrm{Mo}_{3}$ ) [31,32] or in a reduction environment (reduction from $\mathrm{MoO}_{3}$ to $\mathrm{MoO}_{2}$ ), e.g., using a gas such as hydrogen or propane (which is a source of hydrogen), [32,33] involving the thermal-activated adsorption/desorption of oxygen.

As for oxidation [31,32], the feasibility of oxidation even from $\mathrm{MoS}_{2}$ to $\mathrm{MoO}_{2}$ and $\mathrm{MoO}_{3}$ in air has also been shown by green laser irradiation on a millisecond time scale [34].

This annealing and change of oxidation state can be operated starting from deposited $\mathrm{MoO}_{3}$ or $\mathrm{MoO}_{2}$, which can be obtained (i) by controlling the stoichiometry during the growth by the oxygen partial pressure, or (ii) by post-growth processing which includes ion bombardment, which results in the preferential loss of bridging oxygen atoms and oxygen plasmas.

Noteworthy, this innovative way of modulating the oxygen content in oxides has been recently reported for the phase-change material $\mathrm{VO}_{2}$ [35].

Although work is in progress for the practical implementation of this approach to $\mathrm{MoO}_{\mathrm{x}}$, the oxidation/hydrogenation approach has already been implemented in dynamic color devices [36], even using another material (magnesium, Mg), moving it between the two states of oxidation to $\mathrm{MgO}$ and hydrogenation to $\mathrm{MgH}_{2}$.

According to this concept of oxidation/reduction applied to $\mathrm{MoO}_{\mathrm{x}}, \mathrm{MoO}_{3}$ acts as a lossless transparent dielectric in the visible range $\left(E_{\text {gap }}=3 \mathrm{eV}\right.$ depending on the crystallinity), allowing the coupling of narrow modes of the GMR kind and, therefore, opening the possibility of getting vivid colors in the reflectance. On the contrary, $\mathrm{MoO}_{2}$ absorbs the visible spectrum range and Wood anomalies cannot be generated, reflecting a pale color.

For an accurate description of the proposed color display, this paper is divided into various sections. Section 2 is devoted to describing the device design, Section 3 contains details about the numerical simulation method, Section 4 develops the working principle and Sections 5 and 6 contain, respectively, the main results and conclusions of this research.

\section{Pixel Model}

In this research, the reflective display pixel constituted three subpixels, each one associated to a primary color, red $(\mathrm{R})$, green $(\mathrm{G})$, and blue (B). Their reflection properties can be controlled through the optical properties of the $\mathrm{MoO}_{\mathrm{x}}$ material according to what has been described previously. Each subpixel is a reflective diffraction grating based on periodic $\mathrm{MoO}_{\mathrm{x}}$ ribs over a silicon dioxide $\left(\mathrm{SiO}_{2}\right)$ substrate, as shown in Figure 1 (top). A microheater [37] can be located under the substrate to control the annealing process under an oxygen or hydrogen atmosphere.

As $\mathrm{MoO}_{\mathrm{x}}$ is the active tunable material of the reflective display, on and off states can be generated and controlled depending on its stoichiometry. In this work, two measurements of oxygen contents were considered: $x=2.9$ (on) and $x=2.1$ (off). The refractive index of molybdenum oxide for both oxygen contents is also shown in Figure 1 (bottom left and bottom right, respectively). The imaginary part of the refractive index, $k$, is almost zero in the on mode and greater than one in the off state. In the on state, light can travel through it, allowing the generation of a GMR (see Section 4 for more details), which in turn produces vivid colors. However, in the off state, most of the light is absorbed. In this case, resonances are not produced, and a pale unsaturated color is reflected. These optical constants for both oxygen contents were obtained from the literature [38].

In general, the main parameters for the characterization of a diffraction grating are the duty cycle, $D$, the height, $d$, of the ribs, the period, $P$, the polarization (perpendicular to rib direction, $p$-polarization), and the incident angle, $\theta$. The duty cycle $D$ can be considered as the ratio between the width of the rib, $w$, and the period $P$. The first three parameters can be varied for the optimization of the device. The optimization is based on the achievement of the best primary colors, R, G, and B. Each primary color corresponds to a different grating (subpixel) with different parameters. Their suitable combination gives rise to the desired color. 


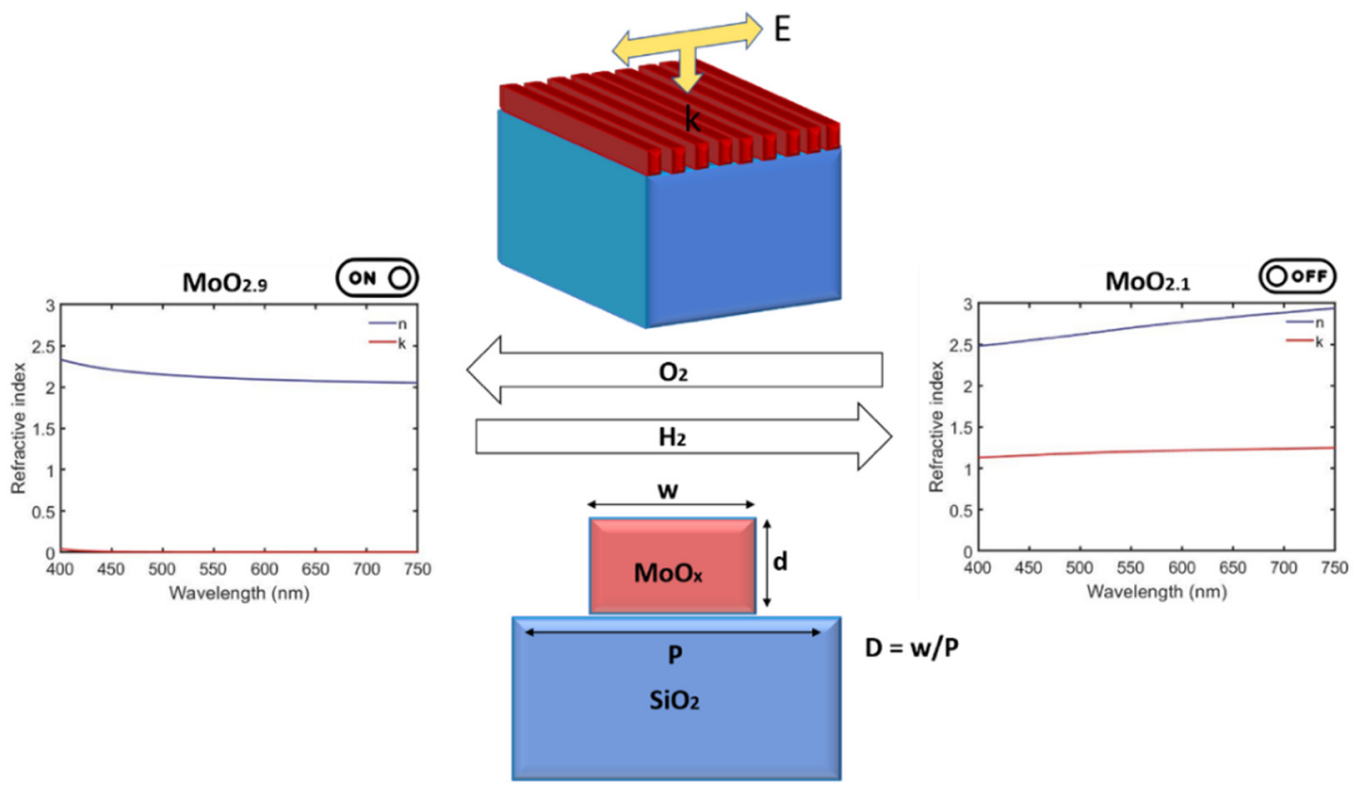

Figure 1. Scheme of the reflected display unit (subpixel associated with a primary color). This design is based on a periodic structure of ribs made of molybdenum oxide $\left(\mathrm{MoO}_{\mathrm{x}}\right)$ over $\mathrm{SiO}_{2}$ substrate. Depending on the amount of oxygen content, $\mathrm{MoO}_{\mathrm{x}}$ is either a transparent medium to visible radiation (on state) or an absorbing one (off state) (see the extinction coefficient $k$ of the refractive index [38]). The transition between both states can be triggered by controlling the amount of $\mathrm{H}_{2}$ or $\mathrm{O}_{2}$ (see $[35,36]$ ).

All results were simulated considering normal incidence and light polarization perpendicular to the rib direction. For simplicity, this polarization was chosen in order to ignore the length of the ribs, allowing the study of the system under a 2D geometrical configuration without losing physical information.

\section{Numerical Simulation Method}

Spectral reflectivity was calculated using finite-difference time-domain (FDTD) simulation (LUMERICAL). This is a numerical analysis technique used for modeling computational electrodynamics (finding approximate solutions to a system of coupled differential equations by time discretization). Nonuniform mesh settings were used in these simulations, and the source used was always a plane wave. Periodicity boundary conditions were used to simulate an infinite number of $\mathrm{MoO}_{\mathrm{x}}$ ribs over a silicon dioxide substrate.

All color simulations within this work assume a standard D65 illuminant, corresponding to average daylight, and a CIE standard observer $\left(2^{\circ}\right)$, representing mean human spectral sensitivity to visible spectrum range under $2^{\circ}$ field observation [39,40]. As sunlight is not polarized and this study was performed for $p$-polarization, some polarizing element should be used in the actual device for the accurate generation of the colors described in this work.

The most common color space to characterize the color generated by reflective displays, as cited in the introduction, is CIE1931. In this space, color is defined by its tristimulus values $(x, y, z)$ in the chromaticity diagram. In this diagram, it is possible to compare the simulated red, green, and blue colors generated by the device with the standard ones (sRGB).

\section{Working Principle: Wood Anomalies and the Guided Mode Resonance}

The color reflected by the designed subpixel device in the on mode is the result of the excitation of guided waves by the grating, also known as Wood anomalies [14]. This high-reflectance phenomenon is based on coupling light propagating in free space to the grating, leading to GMRs [41]. To better understand this phenomenon, spectral reflectivity and the electric and magnetic fields in the near-field regime of the proposed device were 
analyzed for a given subpixel case. To simulate an example, diffraction grating parameters were fixed to $d=150 \mathrm{~nm}, P=340 \mathrm{~nm}$, and $D=0.6$ (normal incidence and $p$-polarization were also assumed).

In Figure 2a,b, the grating spectral reflectivity is shown for the on and off modes, respectively. In the on mode, a narrow reflectance peak appears at a wavelength around $517 \mathrm{~nm}$. There is a single resonance because a mode is excited and guided by the subwavelength grating. On the contrary, the spectral reflectivity in the off state is a flat curve due to the absorbance predominance of $\mathrm{MoO}_{2.1}$, making impossible the generation of GMR.
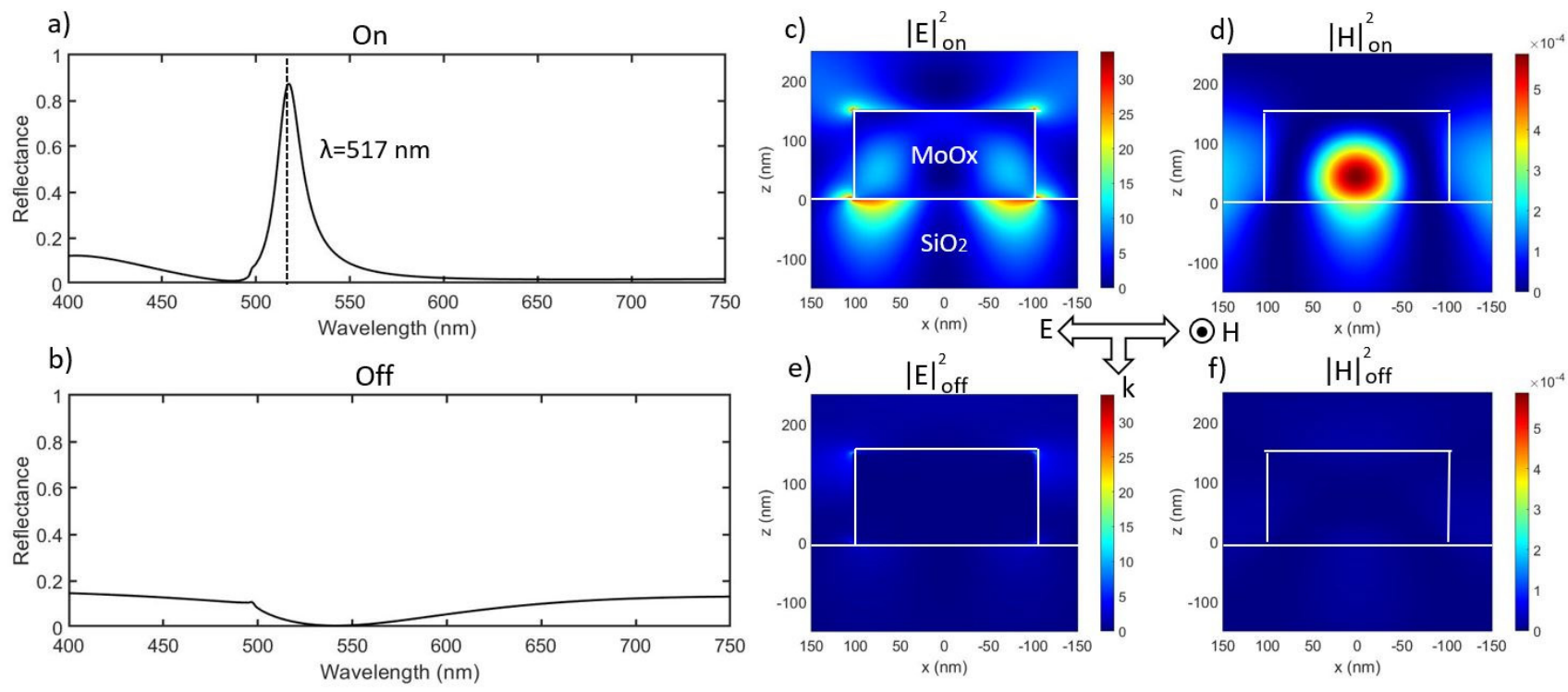

Figure 2. Reflectance of the proposed subpixel for the grating parameters $d=150 \mathrm{~nm}, p=340 \mathrm{~nm}$, and $D=0.6$ for the (a) on and (b) off states, respectively. For the transparent version of the $\mathrm{MoO}_{\mathrm{x}}$ ribs, the reflection of the grating peaks occurs at $\lambda=517 \mathrm{~nm}$. Square module of the electric field in near-field regime when the incident wavelength is $\lambda=517 \mathrm{~nm}$ (spectral position of the reflectance maximum) for the (c) on and (e) off states, respectively. Square modulus of the magnetic field in the near-field regime when the incident wavelength is $\lambda=517 \mathrm{~nm}$ for the (d) on and (f) off states, respectively. The electric field is orthogonal to the grating ribs and the magnetic field is parallel.

The modules of the electric and magnetic fields for the on state and $\lambda=517 \mathrm{~nm}$ are represented in Figure 2c,d, respectively, where guided mode resonances can clearly be observed. Such resonances come from a coupling between nonhomogeneous diffraction orders and the eigenmodes of the grating (Wood anomalies) [41]. As a result, the electric dipole resonance is produced at the $\mathrm{MoO}_{\mathrm{x}}-\mathrm{SiO}_{2}$ interface (the two hotspots in Figure 2c). The coupling of all the dipoles produced in each rib is attributed to the narrow and high reflectance peak. Depending on the number of interacting ribs (i.e., number of interacting dipoles), the electromagnetic response is different. A higher number of ribs leads to more efficient coupling. To assess the importance of this issue, the same simulation shown in Figure 2a was performed but now considering a finite number of ribs (Figure 3a). As this number was increased, the reflectance was more similar to that simulated by periodic boundary conditions. Figure $3 \mathrm{~b}$ shows that a reflectance stationary regime was reached from a number of approximately 150 ribs.

Analogous simulations are presented in Figure 2e,f for the off state. No modes were excited due to the high value of the extinction coefficient $k$ of $\mathrm{MoO}_{2.1}$. 
a)

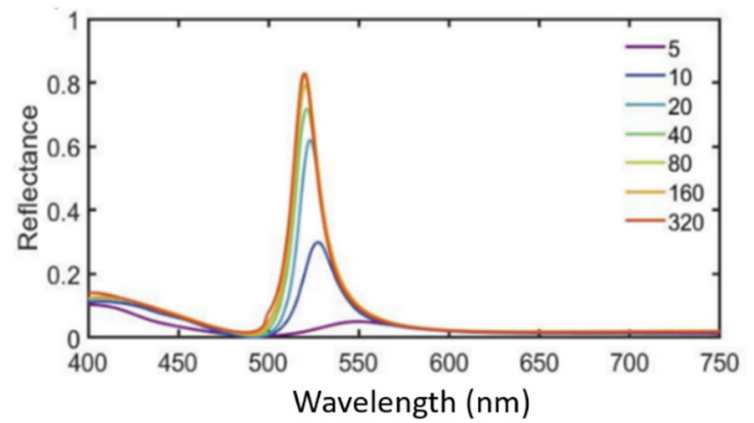

b)

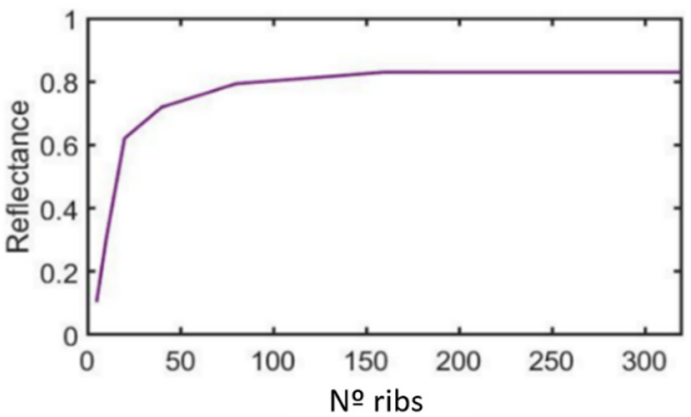

Figure 3. (a) Spectral reflectivity of the proposed device fixing grating parameters to $d=150 \mathrm{~nm}, P=340 \mathrm{~nm}$, and $D=0.6$ (on state) for different numbers of ribs. (b) Maximum reflectance of the resonances generated by changing the number of ribs.

\section{Results}

The results are based on the optimization of each reflective grating subpixel to generate the best primary colors. For normal incidence and $p$-polarization, the way to control the GMR is by varying the duty cycle, the period, or the rib height. Although color does not only depend on spectral reflectivity, for RGB optimization, those magnitudes $(D, P, d)$ were analyzed to generate resonances at $460 \mathrm{~nm}$ (blue), $520 \mathrm{~nm}$ (green), and $620 \mathrm{~nm}$ (red). Moreover, a good contrast between the on and off colors should be addressed. The grating subpixel parameters used for color primary generation are shown in Table 1.

Table 1. Grating subpixel parameters (height $d$, period $P$, and duty cycle $D$ ) for the generation of red, green, and blue colors.

\begin{tabular}{cccc}
\hline & R Subpixel & G Subpixel & B Subpixel \\
\hline$d(\mathrm{~nm})$ & 230 & 125 & 150 \\
\hline$P(\mathrm{~nm})$ & 400 & 340 & 280 \\
\hline$D$ & 0.55 & 0.8 & 0.6 \\
\hline
\end{tabular}

The corresponding spectral reflectivities are shown in Figure $4 \mathrm{a}, \mathrm{b}$ for the on and the off states, respectively. The height, the bandwidth, and the spectral position of those resonances delimited the quality of the generated color. For small bandwidths, monochromatic colors were obtained. However, a lower bandwidth led to less light being reflected. Therefore, the luminosity of the color was too low, generating a very dark color. For this reason, an equilibrium should be required. The resulting colors of these resonances are represented in Figure 4c,d for the on and the off states respectively, and both are plotted in CIE1931 in Figure 4e. On colors (white points) are close to standard RGB coordinates (triangle vertices). However, off colors (black points) are far from those vertices and close to each other, revealing a pale and similar color. A large color gamut can be obtained through this system. 
a)

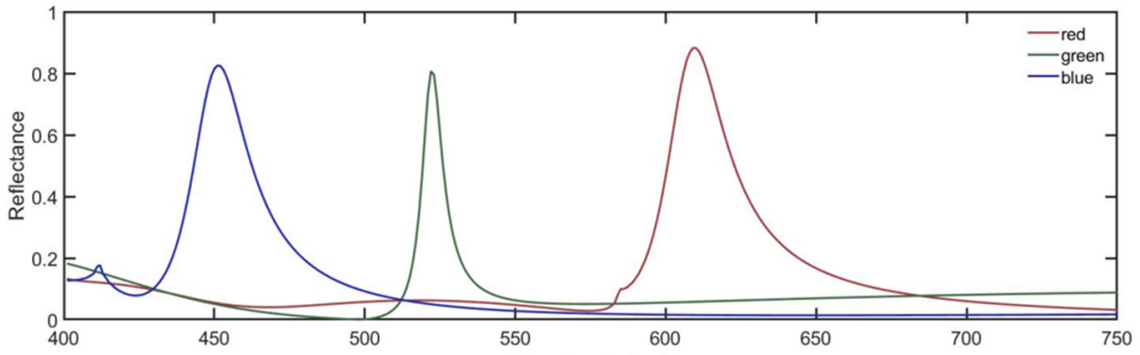

b)

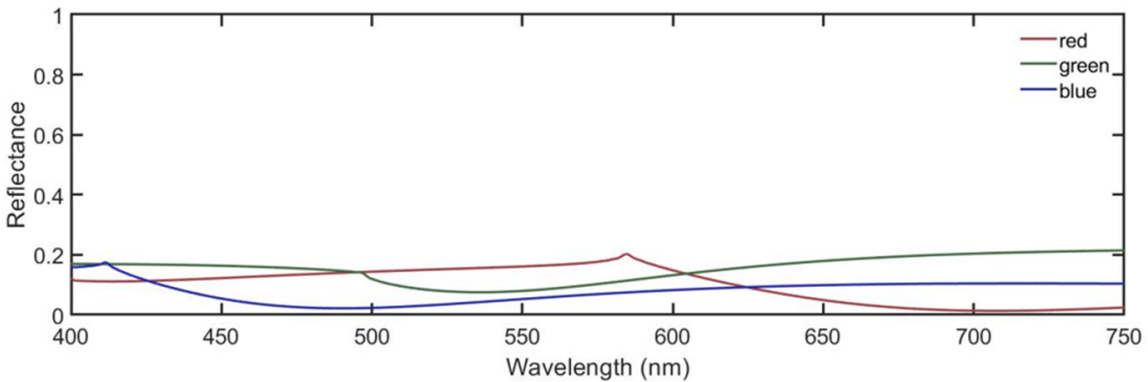

c)

G

B
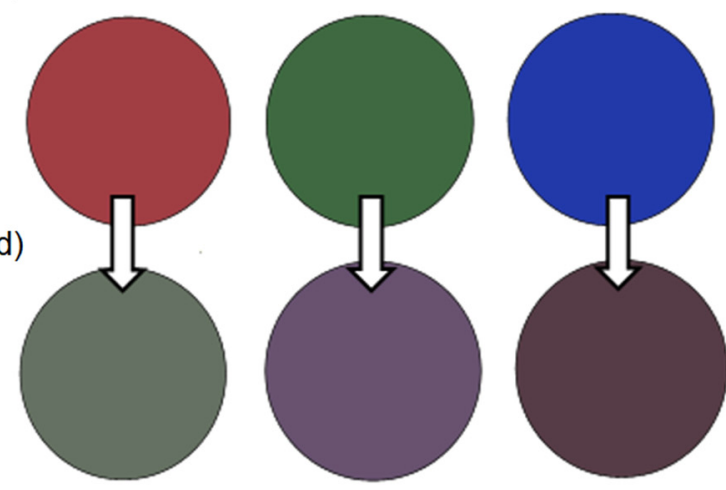

e)

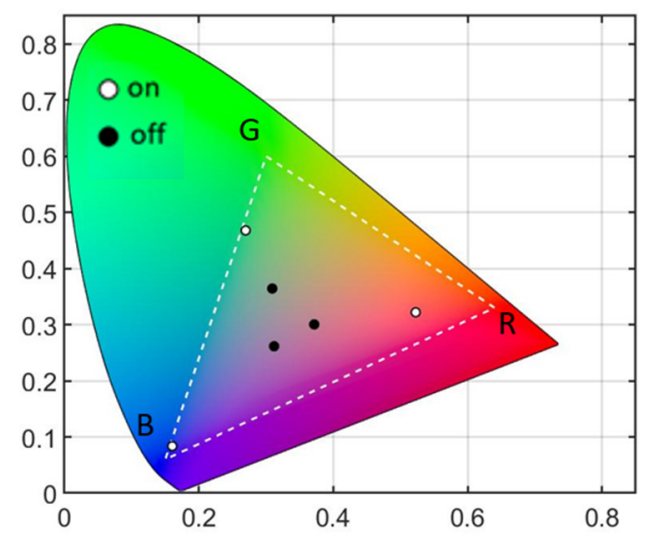

Figure 4. Spectral reflectance of the designed subpixel devices by considering the grating parameters shown in Table 1 for the on (a) and off (b) states, respectively. On (c) and off (d) colors generated by the reflective display pixel, respectively. (e) Representation of those colors in CIE1931 space. The triangle represents RGB standard coordinates, white points (on simulated colors), and black points (off simulated colors). 


\section{Conclusions}

In this paper, a switchable on/off color reflective pixel model based on resonant effects by reflective subwavelength diffraction gratings (subpixel) was designed. The pixel model consisted of a suitable combination of three of those subpixels, each one optimized to generate a primary color, red $(\mathrm{R})$, green $(\mathrm{G})$, or blue $(\mathrm{B})$. The excited resonances in each subpixel can be considered as the collective effect of the electric dipole modes generated in each grating rib for resonant wavelengths. Consequently, the generated color can be tuned spectrally by changing the height, period, and duty cycle of the grating of each subpixel. On/off modes can be generated in each subpixel due to the change in oxidation state of molybdenum oxide $\left(\mathrm{MoO}_{\mathrm{x}}\right)$ from $\mathrm{MoO}_{2}$ to $\mathrm{MoO}_{3}$. This leads to the generation of a wide gamut of colors close to standard SRGB ones for the on mode and a pale color for the respective off state. Compared to other reflective devices based on the Fabry-Perot phenomenon, narrower reflectance peaks can be obtained due to the characteristics of the excited grating resonances, which correspond to the Wood anomalies. This allows the reflection of monochromatic colors and the generation of a large color gamut for applications in color reflective displays.

Author Contributions: Conceptualization and methodology, G.S., F.M. and Y.G.; software, G.S. and Y.G.; formal analysis, all.; resources, M.L. and F.M.; writing-original draft preparation, G.S.; writing-review and editing, G.S., D.O., J.M.S. and F.M.; supervision, F.G., M.L. and F.M. All authors have read and agreed to the published version of the manuscript.

Funding: The authors received funding from the European Union's Horizon 2020 research and innovation program under grant agreement No. 899598-PHEMTRONICS.

Conflicts of Interest: The authors declare no conflict of interest.

\section{References}

1. Shevell, S.K. (Ed.) The Science of Color; Optical Society of America/Elsevier Science: Oxford, UK, 2003. Available online: https://www.sciencedirect.com/book/9780444512512/the-science-of-color (accessed on 9 August 2021).

2. Crone, R.A. A History of Color: The Evolution of Theories of Light and Color; Springer Science \& Business Media: Dordrecht, Germany, 1999. [CrossRef]

3. Schanda, J. (Ed.) Colorimetry: Understanding the CIE System; John Wiley \& Sons, Inc.: Hoboken, NJ, USA, 2007. [CrossRef]

4. Sun, J.; Bhushan, B.; Tong, J. Structural coloration in nature. RSC Adv. 2013, 3, 14862-14889. [CrossRef]

5. Gürses, A.; Açıkyıldız, M.; Güneş, K.; Gürses, M.S. Dyes and Pigments: Their Structure and Properties; Springer: Cham, Switzerland, 2016; pp. 13-29. [CrossRef]

6. Kinoshita, S.; Yoshioka, S. Structural colors in nature: The role of regularity and irregularity in the structure. ChemPhysChem 2005, 6, 1442-1459. [CrossRef] [PubMed]

7. Sung, C.; Han, J.; Song, J.; Ah, C.S.; Cho, S.M.; Kim, T.Y. Reflective-type transparent/colored mirror switchable device using reversible electrodeposition with Fabry-Perot interferometer. Adv. Mater. Technol. 2020, 5, 2000367. [CrossRef]

8. Lin, Z.; Long, Y.; Zhu, X.; Dai, P.; Liu, F.; Zheng, M.; Zhou, Y.; Duan, H. Extending the color of ultra-thin gold films to blue region via Fabry-Pérot-Cavity-Resonance-Enhanced reflection. Optik 2019, 178, 992-998. [CrossRef]

9. Cho, S.M.; Cheon, S.H.; Kim, T.Y.; Ah, C.S.; Song, J.; Ryu, H.; Chu, H.Y. Design and fabrication of integrated Fabry-Perot type color reflector for reflective displays. J. Nanosci. Nanotechnol. 2016, 16, 5038-5043. [CrossRef]

10. Yang, Z.; Zhou, Y.; Chen, Y.; Wang, Y.; Dai, P.; Zhang, Z.; Duan, H. Reflective color filters and monolithic color printing based on asymmetric Fabry-Perot cavities using nickel as a broadband absorber. Adv. Opt. Mater. 2016, 4, 1196-1202. [CrossRef]

11. Zhao, J.; Qiu, M.; Yu, X.; Yang, X.; Jin, W.; Lei, D.; Yu, Y. Defining deep-subwavelength-resolution, wide-color-gamut, and large-viewing-angle flexible subtractive colors with an ultrathin asymmetric Fabry-Perot lossy cavity. Adv. Opt. Mater. 2019, 7, 1900646. [CrossRef]

12. Maystre, D. Theory of Wood's Anomalies. In Plasmonics; Enoch, S., Bonod, N., Eds.; Springer: Berlin/Heidelberg, Germany, 2012; pp. 39-83. [CrossRef]

13. Wood, R.W. On a remarkable case of uneven distribution of light in a diffraction grating spectrum. Proc. Phys. Soc. Lond. 1901, 18, 269-275. [CrossRef]

14. Wang, S.S.; Magnusson, R.J.A.O. Theory and applications of guided-mode resonance filters. Appl. Opt. 1993, 32, $2606-2613$. [CrossRef]

15. Hessel, A.; Oliner, A.A. A new theory of Wood's anomalies on optical gratings. Appl. Opt. 1965, 4, 1275-1297. [CrossRef]

16. Chen, Y.; Liu, W. Design and analysis of multilayered structures with metal-dielectric gratings for reflection resonance and color generation. Opt. Lett. 2012, 37, 4-6. [CrossRef] [PubMed] 
17. Lee, H.S.; Yoon, Y.T.; Lee, S.S.; Kim, S.H.; Lee, K.D. Color filter based on a subwavelength patterned metal grating. Opt. Express 2007, 15, 15457-15463. [CrossRef] [PubMed]

18. Cheong, B.-H.; Prudnikov, O.; Cho, E.; Kim, H.-S.; Yu, J.; Cho, Y.-S.; Choi, H.-Y.; Shin, S.T. High angular tolerant color filter using subwavelength grating. Appl. Phys. Lett. 2009, 94, 213104. [CrossRef]

19. Uddin, M.J.; Magnusson, R. Efficient guided-mode-resonant tunable color filters. IEEE Photonics Technol. Lett. 2012, 24, 1552-1554. [CrossRef]

20. Uddin, M.J.; Magnusson, R. Guided-mode resonant color filter array for reflective displays. In Proceedings of the 2013 IEEE Photonics Conference, Bellevue, WA, USA, 8-12 September 2013; IEEE: Piscataway, NJ, USA, 2013; pp. 28-29. [CrossRef]

21. Wang, W.; Guan, Z.; Xu, H. A high speed electrically switching reflective structural color display with large color gamut. Nanoscale 2021, 13, 1164-1171. [CrossRef]

22. Wuttig, M.; Bhaskaran, H.; Taubner, T. Phase-change materials for non-volatile photonic applications. Nat. Photonics 2017, 11, 465-476. [CrossRef]

23. Vassalini, I.; Alessandri, I.; de Ceglia, D. Stimuli-responsive phase change materials: Optical and optoelectronic applications. Materials 2021, 14, 3396. [CrossRef] [PubMed]

24. Gong, Z.; Yang, F.; Wang, L.; Chen, R.; Wu, J.; Grigoropoulos, C.P.; Yao, J. Phase change materials in photonic devices. J. Appl. Phys. 2021, 129, 030902. [CrossRef]

25. Zylbersztejn, A.; Mott, N.F. Metal-insulator transition in vanadium dioxide. Phys. Rev. B 1975, 11, 4383. [CrossRef]

26. Mott, N.F. Metal-insulator transition. Rev. Mod. Phys. 1968, 40, 677. [CrossRef]

27. Qazilbash, M.M.; Brehm, M.; Chae, B.-G.; Ho, P.-C.; Andreev, G.O.; Kim, B.-J.; Yun, S.J.; Balatsky, A.V.; Maple, M.B.; Keilmann, F.; et al. Mott transition in $\mathrm{VO}_{2}$ revealed by infrared spectroscopy and nano-imaging. Science 2007, 318, 1750-1753. [CrossRef]

28. Zhang, Q.; Li, X.; Ma, Q.; Zhang, Q.; Bai, H.; Yi, W.; Liu, J.; Han, J.; Xi, G. A metallic molybdenum dioxide with high stability for surface enhanced Raman spectroscopy. Nat. Commun. 2017, 8, 14903. [CrossRef]

29. Santos, G.; González, F.; Ortiz, D.; Saiz, J.M.; Losurdo, M.; Moreno, F.; Gutiérrez, Y. Dynamic reflective color pixels based on molybdenum oxide. Opt. Express 2021, 29, 19417-19426. [CrossRef]

30. Imada, M.; Fujimori, A.; Tokura, Y. Metal-insulator transitions. Rev. Mod. Phys. 1998, 70, 1039. [CrossRef]

31. Camacho-López, M.A.; Escobar-Alarcón, L.; Picquart, M.; Arroyo, R.; Córdoba, G.; Haro-Poniatowski, E. Micro-Raman study of the $\mathrm{m}-\mathrm{MoO}_{2}$ to $\alpha-\mathrm{MoO}_{3}$ transformation induced by cw-laser irradiation. Opt. Mater. 2011, 33, 480-484. [CrossRef]

32. Ressler, T.; Wienold, J.; Jentoft, R.E.; Neisius, T. Bulk structural investigation of the reduction of $\mathrm{MoO}_{3}$ with propene and the oxidation of $\mathrm{MoO}_{2}$ with oxygen. J. Catal. 2002, 210, 67-83. [CrossRef]

33. Dang, J.; Zhang, G.-H.; Chou, K.-C.; Reddy, R.G.; He, Y.; Sun, Y. Kinetics and mechanism of hydrogen reduction of $\mathrm{MoO}_{3}$ to $\mathrm{MoO}_{2}$. Int. J. Refract. Met. Hard Mater. 2013, 41, 216-223. [CrossRef]

34. Austin, D.; Gliebe, K.; Muratore, C.; Boyer, B.; Fisher, T.S.; Beagle, L.K.; Benton, A.; Look, P.; Moore, D.; Ringe, E.; et al. Laser writing of electronic circuitry in thin film molybdenum disulfide: A transformative manufacturing approach. Mater. Today 2021, 43, 17-26. [CrossRef]

35. Duan, X.; White, S.T.; Cui, Y.; Neubrech, F.; Gao, Y.; Haglund, R.F.; Liu, N. Reconfigurable multistate optical systems enabled by $\mathrm{VO}_{2}$ phase transitions. ACS Photonics 2020, 7, 2958-2965. [CrossRef]

36. Duan, X.; Kamin, S.; Liu, N. Dynamic plasmonic colour display. Nat. Commun. 2017, 8, 14606. [CrossRef] [PubMed]

37. Broughton, B.; Bandhu, L.; Talagrand, C.; Garcia-Castillo, S.; Yang, M.; Bhaskaran, H.; Hosseini, P. 38-4: Solid-state reflective displays $\left(\mathrm{SRD}^{\circledR}\right)$ utilizing ultrathin phase-change materials. SID Symp. Digest Techn. Papers 2017, 48, 546-549. [CrossRef]

38. Smith, G.B.; Golestan, D.; Gentle, A.R. The insulator to correlated metal phase transition in molybdenum oxides. Appl. Phys. Lett. 2013, 103, 051119. [CrossRef]

39. Capilla, P.; Pujol, J. Fundamentos de Colorimetría; Universitat de València: Valencia, Spain, 2002.

40. Malacara, D. Color Vision and Colorimetry: Theory and Applications; SPIE: Bellingham, WA, USA, 2011. [CrossRef]

41. Sarrazin, M.; Vigneron, J.-P.; Vigoureux, J.-M. Role of Wood anomalies in optical properties of thin metallic films with a bidimensional array of subwavelength holes. Phys. Rev. B 2003, 67, 085415. [CrossRef] 